\title{
Multiple Sclerosis Disease-Modifying Therapy and the COVID-19 Pandemic: Implications on the Risk of Infection and Future Vaccination
}

\author{
Crystal Zheng ${ }^{1} \cdot$ Indrani Kar $^{2} \cdot$ Claire Kaori Chen ${ }^{3} \cdot$ Crystal Sau $^{3,4} \cdot$ Sophia Woodson $^{4} \cdot$ Alessandro Serra $^{4,5}$. \\ Hesham Abboud ${ }^{4}$ (1)
}

Published online: 11 August 2020

(c) Springer Nature Switzerland AG 2020

\begin{abstract}
The coronavirus 2019 (COVID-19) pandemic is expected to linger. Decisions regarding initiation or continuation of diseasemodifying therapy for multiple sclerosis have to consider the potential relevance to the pandemic. Understanding the mechanism of action and the possible idiosyncratic effects of each therapeutic agent on the immune system is imperative during this special time. The infectious side-effect profile as well as the route and frequency of administration of each therapeutic agent should be carefully considered when selecting a new treatment or deciding on risk mitigation strategies for existing therapy. More importantly, the impact of each agent on the future severe acute respiratory syndrome coronavirus type-2 (SARS$\mathrm{CoV}-2$ ) vaccine should be carefully considered in treatment decisions. Moreover, some multiple sclerosis therapies may have beneficial antiviral effects against SARS-CoV-2 while others may have beneficial immune-modulating effects against the cytokine storm and hyperinflammatory phase of the disease. Conventional injectables have a favorable immune profile without an increased exposure risk and therefore may be suitable for mild multiple sclerosis during the pandemic. However, moderate and highly active multiple sclerosis will continue to require treatment with oral or intravenous high-potency agents but a number of risk mitigation strategies may have to be implemented. Immune-modulating therapies such as the fumerates, sphinogosine-1P modulators, and natalizumab may be anecdotally preferred over cell-depleting immunosuppressants during the pandemic from the immune profile standpoint. Within the cell-depleting agents, selective (ocrelizumab) or preferential (cladribine) depletion of B cells may be relatively safer than non-selective depletion of lymphocytes and innate immune cells (alemtuzumab). Patients who develop severe iatrogenic or idiosyncratic lymphopenia should be advised to maintain social distancing even in areas where lockdown has been removed or ameliorated. Patients with iatrogenic hypogammaglobulinemia may require prophylactic intravenous immunoglobulin therapy in certain situations. When the future SARS-CoV-2 vaccine becomes available, patients with multiple sclerosis should be advised that certain therapies may interfere with mounting a protective immune response to the vaccine and that serological confirmation of a response may be required after vaccination. They should also be aware that most multiple sclerosis therapies are incompatible with live vaccines if a live SARS-CoV-2 vaccine is developed. In this article, we review and compare disease-modifying therapies in terms of their effect on the immune system, published infection rates, potential impact on SARS-CoV-2 susceptibility, and vaccine-related implications. We propose risk mitigation strategies and practical approaches to disease-modifying therapy during the COVID-19 pandemic.
\end{abstract}

\section{Introduction}

Coronavirus disease 2019 (COVID-19), caused by the severe acute respiratory syndrome coronavirus type-2 (SARSCoV-2), has quickly become a global pandemic [1]. Among those who require intensive care, the mortality rate is high. It was identified that the SARS-CoV-2 genome is closely

Hesham Abboud

Hesham.abboud@uhhospitals.org

Extended author information available on the last page of the article related to the type- 1 virus SARS-CoV and the Middle Eastern respiratory syndrome coronavirus (MERS-CoV). Therefore, hypotheses can be made about the immune system response to SARS-CoV-2 based on studies in other related corona viruses [2].

Multiple sclerosis (MS) is an immune-mediated central nervous system (CNS) disorder that requires immunosuppressive or immunomodulating disease-modifying therapies (DMTs). The Centers for Disease Control and Prevention designated patients receiving immunotherapies and those with disabilities as possible high-risk groups for 


\section{Key Points}

Some multiple sclerosis therapeutics may increase the risk of SARS-CoV-2 infection.

Some multiple sclerosis therapeutics may have a negative impact on the future SARS-CoV-2 vaccine.

Clinicians should carefully select multiple sclerosis therapeutics during the COVID-19 pandemic and may implement some risk mitigation strategies.

COVID-19 [3]. The MS International Federation published a global advice to the MS community addressing measures to reduce infection risk and general implications related to DMT use [4]. The National MS Society endorsed the MS International Federation global advice and published broad DMT guidelines on their COVID-19 webpage [5]. Patients taking certain DMTs may be at a higher risk for general viral and respiratory infections and infection-related risks. More importantly, some DMTs may have implications on the future SARS-CoV-2 vaccine. Therefore, understanding the impact of each DMT on the immune system, its associated infection risks, and its potential impact on future vaccination is imperative for the safe management of MS during the COVID-19 pandemic. In this review, we evaluate the immune response against SARS-CoV-2 and its future vaccine as it relates to the mechanism of action of each DMT as well as each agent's idiosyncratic effects on the immune system and published rates of infectious side effects. We conclude with a comparison of the relative safety of each DMT in relevance to the COVID-19 pandemic.

\section{SARS-CoV-2 Immune Response}

In addition to angiotensin-converting enzyme-2 receptors, SARS-CoV-2 can enter host cells through the binding of integrins [6]. Integrins are receptors that are located on the surface of various cells in the body and play a role in signaling processes. Following viral infection, the innate immune system is activated. The innate immune response is non-specific and involves activation of macrophages, dendritic cells, and natural killer cells. Some macrophages and dendritic cells are CD52 positive. Typically, when there is a viral invasion, these innate immune cells recognize pathogen-associated molecular patterns [2, 7]. Following detection of pathogen-associated molecular patterns, the downstream signaling cascade is activated to induce antiviral pro-inflammatory cytokines to combat the virus at the entry site including type I and type III interferons (IFNs) [the former includes IFN- $\beta$ ]. Sufficient excretion of IFNs can limit the spread of infection in some cases but SARSCoV-2 has the ability to evade the innate immune system by inhibiting IFNs [8]. COVID-19 infection can also lead to low levels and dysfunction of natural killer cells, macrophages, and dendritic cells. After interaction with innate immunity, the adaptive immune response is activated and can be further subcategorized into cell-mediated and humoral responses. During cell-mediated responses, helper T cells will organize the overall adaptative immune response while cytotoxic $\mathrm{T}$ cells directly attack and kill virally infected cells [2]. COVID-19 infection can cause significant T cell lymphopenia likely due to consumption at inflammatory sites and secondary to the effect of inflammatory cytokines such as interleukin (IL)-6 [9]. This T-cell depletion may help in the spread and worsening severity of the infection. For the humoral immune response, B cells will produce immunoglobulin $\mathrm{M}$ and immunoglobulin $\mathrm{G}(\mathrm{IgG})$ antibodies against the virus, some of which can specifically neutralize the virus [10]. Long-living plasma cells can provide long-term immunity via production of neutralizing antibodies. In addition, virus-specific memory B cells develop and can also help limit future re-infection. However, antibody levels may decrease over time potentially increasing the risk of reinfection. $T$ cells are the most important cell type in the early immune response against coronaviruses while B cells are more implicated in the long-term immunity. Insights from patients with genetic agammaglobulinemia infected with COVID-19 suggest that the immune system can fight and recover from the infection through the effect of $\mathrm{T}$ cells only [11]. However, humoral immunity is not without value in the early immune response against the virus based on reports of severe infection in patients with hypogammaglobulinemia due to common variable immune deficiency [12]. The difference in COVID-19 course between patients with genetic agammaglobulinemia (mild course) and those with common variable immune deficiency (severe course) suggests that the absence of B cells in the former group might attenuate the intensity of the hyperinflammatory cytokine storm [12]. Therefore, B cells might have a protective role against viral spread and reinfection via production of neutralizing antibodies, but may also contribute to the hyperinflammation and cytokine storm stage of the disease through nonantibody-mediated mechanisms [12].

\section{Cytokine Storm and Hyperinflammation}

An individual's body can normally regulate the levels of pro-inflammatory and anti-inflammatory cytokines. However, when a virus enters the host, many cells such as macrophages, lymphocytes, and natural killer cells can become abnormally activated. These cells proceed to release a large 
amount of pro-inflammatory cytokines. This phenomenon is referred to as a cytokine storm [7]. Many studies have shown that the cytokine storm is implicated in the COVID-19 lung injury [7,13]. Common elevated biomarkers include tumor necrosis factor-alpha, IL-1, IL-2, IL-6, IL-7, IL-8, IL-10, and granulocyte-macrophage colony-stimulating factor, among others $[2,7,13-16]$. This cytokine storm can lead to secondary hemophagocytic lymph histiocytosis, which is characterized by fever, cytopenia, pulmonary involvement, and multi-organ failure [14]. Pathogenic dysfunctional granulocyte-macrophage colony-stimulating factor-positive $\mathrm{T}$ cells have been found in abundance in critically ill patients with COVID-19 and are believed to play a pivotal role in this hyperinflammatory stage [17]. Deficiency of T-regulatory cells has also been implicated in the hyperinflammation in patients with COVID-19 [18]. This dysfunctional T-cell processing is similar to changes implicated in the pathogenesis of MS. As mentioned earlier, B cells may also be implicated in the cytokine storm through direct production of IL-6 and other non-antibody-mediated mechanisms [12]. Eventually, this dysregulation in the immune response can lead to immune-mediated lung damage, sepsis, acute respiratory distress syndrome, and even death [2, 14].

\section{Future Vaccines Against SARS-CoV-2}

There are currently multiple pharmaceutical companies attempting to develop a successful SARS-CoV-2 vaccine. One type of vaccine formulation that has become prevalent is the epitope vaccine [2]. Epitopes are short viral protein amino acid sequences that create a more potent and direct effect as opposed to the whole cognate protein. Studies indicated that there is encouraging data to support T-cell epitopes over B-cell epitopes for long-term protection [2]. Other platforms that are being investigated include viral vector vaccines, live-attenuated, inactivated, viral RNA and DNA, and artificial antigen-presenting cell vaccines [19]. Safety parameters related to patients with MS taking certain DMTs will come into play depending on the type of vaccine that best demonstrates efficacy and becomes approved for use. A recent study demonstrated successful development of neutralizing SARS-CoV-2 antibodies similar to those found in convalescent serum after vaccination with the SARSCoV-2 RNA vaccine without trial-limiting safety concerns [20].

\section{Current Multiple Sclerosis Disease-Modifying Therapies}

\subsection{Interferon-Beta (Interferon- $\beta 1 a$ and Interferon- $\beta 1 b)$}

Interferon- $\beta$ agents were the first to receive approval for MS management and are available in subcutaneous and intramuscular formulations. They provide a modest diseasemodifying effect against relapses and accumulation of brain lesions.

\subsubsection{Mechanism of Action and Impact on the Immune System}

Interferon- $\beta$ is an immunomodulating agent. It directly increases the expression of anti-inflammatory cells and decreases the expression of pro-inflammatory cytokines [21]. It also decreases the number of inflammatory cells crossing the blood-brain barrier and increases nerve growth factor production. Last, the number of CD56 natural killer cells is increased by IFN- $\beta$; these cells efficiently produce anti-inflammatory mediators and potentially have the ability to limit neuronal inflammation. Side effects may include rare leukopenia, lymphopenia, and lymphadenopathy [22, 23].

\subsubsection{Infectious Side Effects}

Upper respiratory tract infections (URTIs) were observed with IFN- $\beta 1$ a ( $14 \%$ vs $12 \%$ placebo) [22]. Interferon- $\beta 1 \mathrm{~b}$ had lower incidences of infectious side effects [23]. However, IFN- $\beta 1 \mathrm{~b}$ formulations contain albumin that may also increase the risk of viral transmission [24]. Interferons are not associated with opportunistic or severe infections.

\subsubsection{Potential Relevance to the COVID-19 Pandemic and Possible Risk Mitigation Strategies}

As IFN- $\beta$ does not act primarily by depleting lymphocytes and because the associated lymphopenia is often rare and mild, it is unlikely to impact the early or delayed immune response against SARS-CoV-2 or increase infection susceptibility significantly. In addition, IFN $-\beta$ may have a beneficial antiviral effect against SARS-CoV-2 when combined with conventional antiviral agents as shown in a recent, openlabel phase II clinical trial [25]. Therefore, it is likely safe to continue ongoing IFN $-\beta$ treatment during the pandemic even in patients with COVID-19 infection. It is also safe to start IFN- $\beta$ treatment in patients with newly diagnosed MS. Based on influenza vaccine studies, IFN- $\beta$ does not 
seem to reduce the protective immune response to vaccines and will likely be compatible with the future SARS-CoV-2 viral protein or inactivated vaccine [26]. Compatibility with live-attenuated vaccines is unknown. The subcutaneous or intramuscular routes of administration are safe from the exposure risk standpoint compared with intravenous DMTs that require administration at infusion centers or hospital settings. Although the optimal safety profile of IFN- $\beta$ compared with other DMTs makes it a suitable option for patients with mild MS during the pandemic, its potency is low compared with the newer agents and it may not be the best choice for patients with highly active MS or who have several negative outcome predictors $[27,28]$.

\subsection{Glatiramer Acetate}

Glatiramer acetate (GA) is a subcutaneous injectable that provides a modest reduction in the annualized relapse rate.

\subsubsection{Mechanism of Action and Impact on the Immune System}

Glatiramer acetate is a synthetic polypeptide that is structurally similar to myelin basic protein; an important component of myelin sheath. It competes with myelin antigens for the interaction with major histocompatibility complex type-2 molecules on antigen-presenting cells. This results in the prevention of a $\mathrm{T}$-cell response against myelin and activation of T-helper type- 2 cells to secrete anti-inflammatory cytokines reducing CNS inflammatory demyelination [29]. There may be a potential interference with the detection of foreign antigens with this agent.

\subsubsection{Infectious Side Effects}

When compared with placebo, GA had a slightly higher incidence of overall infection (30\% vs $28 \%$ ), bronchitis (6\% vs $5 \%$ ), influenza (14\% vs $13 \%$ ), nasopharyngitis (11\% vs $9 \%$ ), and viral URTIs (3\% vs 2\%) [30]. However, this medication is typically not known to cause opportunistic or severe infections.

\subsubsection{Potential Relevance to the COVID-19 Pandemic and Possible Risk Mitigation Strategies}

As GA does not deplete lymphocytes, it is unlikely to impact the early or delayed immune response against SARS-CoV-2 or increase infection susceptibility. Therefore, it is likely safe to continue ongoing treatment with this agent during the pandemic even in patients with COVID-19 infection. It is also safe to start GA treatment in patients with newly diagnosed MS during the pandemic. One study found a potential negative impact on the protective immune response to the influenza vaccine in patients taking GA but several other studies did not find a negative impact [31-33]. Overall, the impact of GA on the future SARS-CoV-2 viral protein or inactivated vaccine is likely limited and safer in comparison to cell-depleting DMTs. The subcutaneous route of administration is safe from the exposure risk standpoint compared with intravenous agents. Like IFN- $\beta$, GA has a favorable safety profile but its potency is low, thus its use during the pandemic may need to be restricted to patients with mild MS [34].

\subsection{Teriflunomide}

Teriflunomide is an oral agent that provides modest efficacy in preventing relapses and lesion accumulation in MS. It was approved in 2012 after two randomized, double-blind, placebo-controlled phase III trials in relapsing-remitting MS and one in clinically isolated syndrome [35].

\subsubsection{Mechanism of Action and Impact on the Immune System}

Teriflunomide is a dihydroorotate dehydrogenase inhibitor. Dihydroorotate dehydrogenase is a key mitochondrial enzyme in the de novo pyrimidine synthesis that is required by rapidly dividing cells. Ultimately, inhibition of this enzyme reduces replication of auto-reactive lymphocytes [29]. Immune side effects include rare lymphopenia (12\%) and neutropenia (16\%) [36].

\subsubsection{Infectious Side Effects}

Teriflunomide $14 \mathrm{mg}$ had slightly higher incidences of infections when compared with placebo including URTIs ( $9 \%$ vs $7 \%$ ), bronchitis ( $8 \%$ vs $6 \%$ ), and sinusitis (6\% vs $4 \%$ ) [36]. Rare cases of tuberculosis were also seen. There have also been reports of reactivation of cytomegalovirus hepatitis. In post-marketing experience, there have been fatal cases of Klebsiella, Pneumocystis jiroveci, and Aspergillus pneumonia, but these patients had either an underlying comorbidity or were co-treated with other immunosuppressants.

\subsubsection{Potential Relevance to the COVID-19 Pandemic and Possible Risk Mitigation Strategies}

By reducing the proliferation of reactive lymphocytes and in view of its infectious side-effect profile, it is possible that teriflunomide my slightly increase the susceptibility to SARS-CoV-2. However, it may also have some beneficial antiviral effects [37]. Therefore, it is perhaps relatively safe to continue ongoing treatment with teriflunomide 
and to start it in patients newly diagnosed with mild MS during the pandemic. Its safety in patients infected with COVID-19 is unclear but it is likely safe to continue in asymptomatic or mildly symptomatic patients. One fatal case of COVID-19 infection in a patient taking teriflunomide has been reported but the patient had advanced secondary progressive MS and comorbid myotonic dystrophy [38]. Seven other cases of COVID-19 infection in patients taking teriflunomide have been reported to the time of this writing, all with self-limiting courses despite continued teriflunomide therapy during the infection in most of them [39-41]. One additional self-reported case with full recovery at home has been described in a paper surveying self-reported cases on social media [42]. Based on influenza vaccine studies, teriflunomide is unlikely to reduce the protective immune response against the future SARS-CoV-2 viral protein or inactivated vaccine [43]. In addition, successful development of anti-SARS-CoV-2 antibodies at levels comparable to patients not receiving immunotherapies has been described in a patient taking teriflunomide after COVID-19 infection [41]. Live-attenuated vaccines are not recommended with teriflunomide. The oral route is safe compared with intravenous agents from the exposure risk standpoint. Its low potency makes it unsuitable for patients with highly active MS or several negative predictors $[44,45]$

\subsection{Fumarates}

Dimethyl fumarate (DMF) was first approved in 2013 for relapsing forms of MS (RMS) after it achieved primary outcome in two randomized, placebo-controlled, double-blind, phase III clinical trials [29]. Diroximel fumarate was more recently approved in 2019 based on bioequivalence studies showing similar bioavailability of the active metabolite to DMF. Both oral medications have similar efficacy but diroximel fumarate has fewer gastrointestinal adverse effects [46].

\subsubsection{Mechanism of Action and Impact on the Immune System}

The mechanism of action of these medications is unknown; however, they are believed to cause immunomodulation via inhibition of the Nrf-2 protein ultimately inhibiting inflammatory cascades [29]. One major idiosyncratic adverse effect is lymphopenia, which occurs in $37 \%$ of patients [47]. However, severe lymphopenia $\left(<500 / \mathrm{mm}^{3}\right)$ occurs in only $8 \%$ of patients [47]. Differential lymphocyte count is monitored every 3-6 months during therapy and monthly if the absolute lymphocyte count (ALC) falls below $500 / \mathrm{mm}^{3}$.

\subsubsection{Infectious Side Effects}

The incidences of overall infections (60\% vs 58\%) and serious infections ( $2 \%$ vs $2 \%$ ) were similar between DMF and placebo in MS clinical trials including those experiencing lymphopenia [48]. However, there have been case reports of progressive multifocal leukoencephalopathy (PML) reported with DMF mainly in patients with prolonged moderate-tosevere lymphopenia $\left(<800 / \mathrm{mm}^{3}\right)$, although rare cases have occurred without significant lymphopenia as well [49].

\subsubsection{Potential Relevance to the COVID-19 Pandemic and Possible Risk Mitigation Strategies}

It is unknown if the fumarates increase the risk of SARSCoV-2 infection. Based on their immune profile, it is possible that they may increase the susceptibility to SARSCoV-2 in patients with moderate-to-severe lymphopenia but are likely safe in patients without lymphopenia or with mild lymphopenia (ALC $>800 / \mathrm{mm}^{3}$ ). Therefore, it is reasonable to continue ongoing treatment unless ALC goes below $800 / \mathrm{mm}^{3}$. In this situation, interruption of treatment and a monthly ALC check are advisable. Patients with persistent severe lymphopenia should be switched to another DMT after allowing ALC to improve. It is likely safe to start patients newly diagnosed with MS on one of the fumarates but ALC monitoring is important after starting treatment. The need for periodic laboratory monitoring increases the exposure risk at the medical laboratory but the oral route is safer compared with intravenous agents. It is likely safe to continue treatment with the fumarates in non-lymphopenic patients with MS with asymptomatic or mildly symptomatic SARS-CoV-2 infection. Two patients taking DMF with COVID-19 infection have been reported [38]. Both patients did not have lymphopenia at baseline and both had full recovery despite continuation of DMF [38]. Seven patients with suspected COVID-19 (not confirmed by polymerase chain reaction) were reported from Italy during the peak of the epidemic, all with favorable outcomes despite continued treatment with DMF during the infection [50]. Notably, most patients had normal or only mildly decreased lymphocyte counts at the time of infection except one patient with grade 2 lymphopenia. Two additional self-reported cases with good outcomes after COVID-19 infection were included in the paper surveying social media self-reports [42]. Based on various vaccine studies, the fumarates do not seem to reduce the immune response against viral vaccines and are not likely to impact immunity against the future SARS-CoV-2 viral protein or inactivated vaccine in non-lymphopenic patients [51]. Compatibility with live-attenuated and viral vector vaccines is unknown. 


\subsection{Sphingosine-1-Phosphate Modulators}

Fingolimod was the first sphingosine-1-phosphate (S1P) modulator and the first oral agent approved for RMS in 2010. It met the primary outcome in three randomized, doubleblind, phase III clinical trials, two against placebo and one against IFN- $\beta 1$-a [29]. Siponimod and ozanimod followed and were approved in 2019 and 2020, respectively [35, 52]. They both are more selective to the S1P1 and S1P5 subtypes and have less bradycardic side effects compared with fingolimod, therefore eliminating the need for first-dose observation in healthy individuals.

\subsubsection{Mechanism of Action and Impact on the Immune System}

Sphingosine-1-phosphate modulators prevent egress of T cells from lymph nodes [29]. Hence, the number of lymphocytes available to the CNS is decreased, and there is reduced central inflammation but lymphocytes are not depleted. The circulating lymphocytes as represented by the ALC will typically decrease with these agents but remain above 200/ $\mathrm{mm}^{3}$ in most patients.

\subsubsection{Infectious Side Effects}

All three medications cause a dose-dependent reduction in peripheral lymphocyte count and therefore, may increase the risk of infections. Fingolimod studies showed an overall infection incidence (72\%) and serious infection incidence (2\%) that were similar to placebo [53]. Influenza (13\% vs $10 \%)$ and herpes viral infections (9\% vs $8 \%$ ) were higher when compared with placebo. Fatal cases of disseminated herpetic infections have occurred with fingolimod. Siponimod and ozanimod demonstrated similar infectious side effects in clinical trials $[54,55]$. Progressive multifocal leukoencephalopathy is also a risk with this class of DMTs.

\subsubsection{Potential Relevance to the COVID-19 Pandemic and Possible Risk Mitigation Strategies}

It is unknown if S1P modulators increase the risk of SARS-CoV-2 infection. By reducing peripheral lymphocytes, these agents may potentially increase the susceptibility to SARS-CoV-2 as evidenced by the increased susceptibility to other viral infections. However, a potential beneficial effect in patients with COVID-19 with a cytokine storm has been proposed and a clinical trial of fingolimod in patients with COVID-19 is currently ongoing (ClinicalTrials.gov Identifier: NCT04280588). It is likely safe to continue ongoing treatment during the pandemic provided the ALC is higher than $200 / \mathrm{mm}^{3}$ and is likely safe (and potentially beneficial) to even do so in patients infected with COVID-19. Two cases of COVID-19 worsening after stopping fingolimod have been reported $[56,57]$. Treatment interruption may be considered if ALC goes below $200 / \mathrm{mm}^{3}$ although the impact of this low level of circulating lymphocytes on infection risk is not well defined [58]. Stopping fingolimod has been linked to severe rebound MS activity, thus timely initiation of another potent DMT is recommended to avoid the need for hospitalization and the increased exposure risk [59]. In addition to the two cases mentioned above, six additional cases of COVID-19 infection in patients with MS taking fingolimod have been reported to the time of this writing [38, 41, 60-62]. Four additional self-reported cases on Twitter have been reported as well [42]. All patients recovered fully although a severe course was described in two patients who stopped fingolimod treatment during the infection as mentioned earlier and in one additional patient who improved after delaying fingolimod treatment. Some of the patients with a mild course temporarily interrupted fingolimod treatment during their COVID-19 infection and some continued treatment without interruption. At the time of this writing, no cases of COVID-19 infections in patients treated with siponimod or ozanimod have been reported.

It is relatively safe to start S1P modulators in patients with newly diagnosed MS during the pandemic but the impact on the future SARS-CoV-2 vaccine must be considered. Fingolimod has been shown to dampen both the cellular and humoral protective immune responses against vaccines [63]. In addition, one of the reported patients with COVID-19 infection taking fingolimod was noted to have attenuated production of anti-SARS-CoV-2 antibodies after exposure [41]. Fingolimod is also incompatible with liveattenuated vaccines and its impact on viral vector vaccines is unknown. For patients who receive the future SARS-CoV-2 viral protein or inactivated vaccine while taking an S1P modulator, it is advisable to check serology after vaccination to ensure an adequate immune response has been mounted. Like the fumarates, the oral route of S1P modulators is preferable compared with intravenous agents but the need for periodic laboratory monitoring increases the exposure risk.

\subsection{Natalizumab}

Natalizumab is the first monoclonal antibody to become approved for use in RMS in 2004. It has a high potency against MS relapses and lesion accumulation. It reached the primary outcome in two phase III, placebo-controlled clinical trials, one as monotherapy and one as combination therapy with IFN- $\beta 1-\mathrm{a}$ [29]. 


\subsubsection{Mechanism of Action and Impact on the Immune System}

Natalizumab acts as an antagonist to alpha- 4 integrin on the surface of leukocytes, consequently blocking their interaction with vascular cell adhesion molecules and preventing leukocyte migration to the CNS [29]. It is a nondepleting immunomodulator and it has not been linked to lymphopenia.

\subsubsection{Infectious Side Effects}

It is known that natalizumab increases the risk of PML more than all other DMTs and monitoring antibodies to the causative John Cunningham virus (JCV) is mandatory during treatment. High levels of JCV-IgG indicate viral exposure and increase the risk of PML. Respiratory infections including URTIs ( $22 \%$ vs $16 \%$ placebo), influenza ( $12 \%$ vs $5 \%$ placebo), and sinusitis ( $8 \%$ vs $4 \%$ placebo) were commonly observed in patients taking natalizumab [64]. Fatal cases of herpetic encephalitis and meningitis were reported in the post-marketing data.

\subsubsection{Potential Relevance to the COVID-19 Pandemic and Possible Risk Mitigation Strategies}

Being a non cell-depleting agent, it is unlikely that natalizumab significantly increases SARS-CoV-2 susceptibility. Its infectious side-effect profile suggests a mild increase in the susceptibility to respiratory viral infections. A possible beneficial effect in patients infected with COVID19 has been proposed via its action on integrin receptors [6]. Based on influenza vaccine studies, it is also unlikely that natalizumab will have a negative impact on the future SARS-CoV-2 viral protein or inactivated vaccines [65]. Its compatibility with live-attenuated and viral vector vaccines is unknown. Overall, it is likely safe to continue ongoing treatment with natalizumab during the COVID-19 pandemic including in infected patients. It is also likely safe to start as a new treatment in patients who are JCV-IgG negative and is perhaps the safest potent DMT for patients with highly active MS during the pandemic. However, some experts have raised theoretical concerns that this medication may reduce trafficking of lymphocytes in the lungs and mucosa potentially increasing viral shedding [66]. Similar to the predisposition to PML, the reduced immune surveillance in the CNS also raises concerns about the potential for SARS-CoV-2 encephalitis if natalizumab is used in patients with COVID19 [66]. As opposed to its favorable immune profile, the intravenous route of administration of this medication is not ideal during the pandemic as it increases the exposure risk at infusion centers. The monthly infusion frequency is the highest among all intravenous DMTs further increasing the exposure risk. Using an off-label extended dosing interval may be an equally effective and safer alternative to standard dosing during the pandemic especially in high-risk patients (old age, cardiopulmonary comorbidity) [67]. At the time of this writing, two cases of COVID-19 infection in patients with MS taking natalizumab have been reported [68, 69]. Both patients had mild courses with complete recovery. One patient was receiving the standard regimen and the other patient was on the extended dosing schedule. Neither of the patients had neurological symptoms or suspicion for SARSCoV-2 encephalitis.

\subsection{Ocrelizumab}

The FDA approved ocrelizumab in 2017 for both RMS and primary progressive MS (PPMS). It has shown high efficacy against relapses and lesion accumulation in the brain compared with IFN- $\beta 1 \mathrm{a}$ in two randomized, double-blind, double-dummy, phase III clinical trials in RMS [28]. It showed modest efficacy against disability progression compared with placebo in a randomized, double-blind, phase III clinical trial in PPMS [70].

\subsubsection{Mechanism of Action and Impact on the Immune System}

Ocrelizumab is a humanized MAB that targets $C D 20$ on the surface of $B$ cells causing prolonged selective B-cell lymphopenia [29]. It can cause a reduction in the total ALC in about $25 \%$ of patients [58]. Although ocrelizumab does not target plasma cells, prolonged depletion of memory B cells can lead to hypogammaglobulinemia in some patients as seen with other B-cell therapies on long-term treatment [71, 72].

\subsubsection{Infectious Side Effects}

Patients taking ocrelizumab in both RMS and PPMS trials experienced a higher incidence of infections. In RMS trials, the incidence of infections was $58 \%$ in ocrelizumab-treated patients compared with $52 \%$ in IFN- $\beta 1$ a-treated patients. Additionally, incidences of URTIs ( $40 \%$ vs $33 \%$ ), lower respiratory tract infection (LRTI) (8\% vs 5\%), herpes zoster ( $2.1 \%$ vs $1.0 \%)$, and herpes simplex $(0.7 \%$ vs $0.1 \%)$ were also higher in the ocrelizumab-treated group [73]. In PPMS trials, the incidence of infections was $70 \%$ in ocrelizumabtreated patients compared with $68 \%$ in the placebo group. Incidences of URTI ( $49 \%$ vs $43 \%$ ), LRTI ( $10 \%$ vs $9 \%$ ), and oral herpes $(2.7 \%$ vs $0.8 \%)$ were also higher in the ocrelizumab-treated group. 


\subsubsection{Potential Relevance to the COVID-19 Pandemic and Possible Risk Mitigation Strategies}

The risk of SARS-CoV-2 infection in patients taking ocrelizumab is not fully known. As it mainly targets B cells, ocrelizumab likely has less impact on the early immune response against the virus compared with $\mathrm{T}$-cell targeting or non-selective immunosuppressive agents. However, in addition to their role in humoral immunity, B cells also act as antigen-presenting cells to $\mathrm{T}$ cells and may be implicated in their early activation [74]. Therefore, it is possible that ocrelizumab may increase the susceptibility to SARS-CoV-2 as demonstrated in a recent case series [75]. More importantly, B-cell depletion may impair long-term immunity against the virus and may increase re-infection risk [2]. Failure to develop anti-SARS-CoV-2 antibodies after COVID19 infections in patients treated with ocrelizumab has been frequently reported in the recent literature [76-79]. Although this impairment of the humoral response did not result in a more severe infection in most of the reported cases, it may predispose recovering patients to repeated infection.

Patients with ocrelizumab-related hypogammaglobulinemia may be particularly vulnerable to infection-related risks [72]. Acquired hypogammaglobulinemia in patients treated with anti-CD20 agents resembles the immune dysfunction in patients with common variable immune deficiency who are prone to severe COVID-19 infection [12]. The intravenous route increases the exposure risk at infusion centers but the exposure risk is less compared with natalizumab because of the less frequent dosing (6-monthly maintenance infusions). Like other B-cell therapies, ocrelizumab may reduce the humoral protective response against the future SARS-CoV-2 viral protein or inactivated protein and is incompatible with live-attenuated vaccines [80]. Compatibility with viral vector vaccines is unknown. The negative impact on the protective immune response against the future SARS-CoV-2 vaccine is further supported by the blunted antibody response in ocrelizumab-treated patients exposed to the virus.

There are more COVID-19 cases reported with antiCD20 agents than all other DMT classes which is, at least in part, owing to the popularity of this class in modern MS treatment trends. Recent case series and pharmacovigilance reports suggest that the risk and severity of COVID19 infection in patients treated with anti-CD20 agents (ocrelizumab or rituximab) is not different from the general population, although critical and fatal cases have happened in a subset of patients [81, 82]. One case series suggested increased susceptibility to SARS-CoV-2 in patients receiving anti-CD20 agents as previously mentioned [75]. However, several case reports described favorable outcomes in ocrelizumab-treated patients after COVID-19 infection $[83,84]$. The discrepancy and variability of the
COVID-19 disease course in patients treated with antiCD20 therapies could be anecdotally explained by the fact that B cells could have both a beneficial and a harmful effect in SARS-CoV-2-related infection. The beneficial effect is attained via production of anti-viral neutralizing antibodies while the harmful effect is mediated through production of IL-6 and contribution to the hyperinflammatory cytokine syndrome [12].

To mitigate ocrelizumab-related risks during the pandemic, it is perhaps reasonable to space out infusions guided by CD19 counts. Clinicians may delay ocrelizumab redosing in patients with sustained CD19 depletion and in patients infected with COVID-19. Replacement therapy with intravenous immunoglobulin should be considered in patients with severe hypogammaglobulinemia as a prophylactic measure in uninfected patients and to complement supportive treatment in patients infected with COVID-19. For patients with newly diagnosed MS, the decision to start ocrelizumab as a new therapy should be considered with caution given its potential impact on infection risk and future vaccination. Patients with mild-to-moderate MS are better started on non-depleting DMTs during the pandemic. For highly active MS, natalizumab may be a safer and equally potent option for patients who are JCV-IgG negative. Ocrelizumab use may need to be temporarily restricted to patients with highly active MS who are JCV$\mathrm{IgG}$ positive and those who had already not responded to other agents. Ocrelizumab is also the only DMT indicated in PPMS and should continue to be used in those patients. However, in patients with advanced PPMS with bulbar dysfunction and/or those who are wheelchair bound, the benefits of starting ocrelizumab should be weighed against the risk of immunosuppression in this infection vulnerable group. Post-vaccination serology should be checked in ocrelizumab-treated patients who receive the future SARSCoV-2 viral protein or inactivated vaccine to confirm the development of protective immunity. Vaccination should take place towards the end of the 6-month cycle, preferably 4 weeks prior to the next dose to mitigate the negative impact on vaccination response similar to the common practice in rituximab-treated patients [75].

\subsection{Alemtuzumab}

Alemtuzumab is a highly potent immunosuppressant that is given intravenously to reduce MS relapses and lesion accumulation in the brain. It was approved for RMS in 2014 after it reached the primary outcome in two randomized double-blind, phase III clinical trials against IFN- $\beta 1-a$, one in treatment-naïve patients and the other in patients who did not respond to first-line agents [29]. 


\subsubsection{Mechanism of Action and Impact on the Immune System}

Alemtuzumab is a humanized MAB that targets CD52 receptors on the surface of mature lymphocytes [29]. Alemtuzumab causes generalized lymphopenia with a more prolonged effect on T cells. Because of the broad initial lymphopenia, the immune system may be reset at the time of immune cell reconstitution becoming less pathogenic to the CNS. This may eliminate the need for life-long treatment as patients may experience sustained remission after two or three treatment cycles. However, because of its potent effect on immune cells and the early B-cell reconstitution in the absence of $\mathrm{T}$ cells, alemtuzumab can cause several autoimmune disorders including thyroid disease, idiopathic thrombocytopenia, and glomerulonephritis. Alemtuzumab also alters the innate immunity by acting on CD52-positive macrophages and dendritic cells [85]. It can also cause neutropenia and pancytopenia.

\subsubsection{Infectious Side Effects}

Patients treated with alemtuzumab have a higher risk of infection. In clinical studies, infections occurred in $71 \%$ of patients taking alemtuzumab vs $53 \%$ of patients taking IFN- $\beta 1$ a [86]. These infections included nasopharyngitis (25\% vs $19 \%$ ), URTIs (16\% vs $13 \%$ ), sinusitis (11\% vs $8 \%$ ), herpetic infections ( $16 \%$ vs $3 \%$ ), influenza ( $8 \%$ vs $6 \%$ ), and bronchitis ( $7 \%$ vs $4 \%$ ). Serious infections occurred in $3 \%$ of patients taking alemtuzumab vs $1 \%$ of patients taking IFN$\beta 1$ a. These included pneumonia and herpes zoster.

\subsubsection{Potential Relevance to the COVID-19 Pandemic and Possible Risk Mitigation Strategies}

Because of its effect on both T and B cells as well as some innate immune cells, alemtuzumab may impact the early and long-term immunity against SARS-CoV-2 increasing infection susceptibility and reinfection rates. These potential negative effects are expected during the cell-depletion phase especially in the first 6 months after dosing when maximum lymphopenia is expected. Alemtuzumab can potentially reduce the humoral and cellular responses against the future SARS-CoV-2 viral protein or inactivated vaccine if administered during the cell-depletion phase. It will be incompatible with the future live-attenuated vaccine if one is developed. Its compatibility with viral vector vaccines is unknown. The intravenous route of administration increases the exposure risk compared with the oral or subcutaneous/intramuscular routes but the infusion frequency is less than that of natalizumab and ocrelizumab considering the limited number of infusions needed per lifetime (five daily infusions initially, then three daily infusions after 1 year). However, the need for monthly blood and urine tests to monitor for autoimmune diseases further increases the exposure risk at the medical laboratory or from home laboratory technicians.

Two separate case reports of COVID-19 infection during the cell-depletion phase of alemtuzumab therapy have been described at the time of this writing $[87,88]$. Both patients received their second cycle of alemtuzumab therapy during the peak of the pandemic and developed the infection shortly after receiving the second cycle ( 1 week after treatment in one patient and 2 months after treatment in the other). At the time of infection, one patient had severe (grade 4) lymphopenia while the other had moderate (grade 2) lymphopenia. It is unclear if treatment with alemtuzumab increased the susceptibility to SARS-CoV-2 infection in those patients but disease severity was limited and both patients recovered without a need for hospitalization. However, both patients were in their 30's with minimal neurological deficits and had no other comorbid conditions.

Patients who are in the immune reconstitution phase after completing two or three rounds of alemtuzumab and returning to normal or near-normal lymphocyte counts are likely not at increased risk for SARS-CoV-2 infection. A recent study of ten patients mostly in the immune reconstitution phase found only two patients with suspected mild COVID-19 infection (polymerase chain reaction testing not performed) based on symptoms and known exposure to family members infected with COVID-19 [89]. Both patients did well and did not require hospitalization. One additional patient from the same study did not develop any COVID-19 symptoms despite exposure to an infected family member. The authors of this study speculated that immune reconstitution after alemtuzumab therapy may provide partial protection against severe COVID-19 infection, albeit this concept clearly needs further confirmation.

For risk mitigation in patients who have received one cycle of alemtuzumab, delaying the second cycle or switching to a safer DMT should be considered especially in patients with COVID-19 infection. The fact that most infectious side effects occur closer to dose initiation during maximum lymphopenia, including the two reported COVID-19 confirmed cases, suggests that redosing alemtuzumab during the pandemic in high-risk areas may be unsafe. This approach has been proposed by several published expert opinions and treatment guidelines including those published by the Association of British Neurologists and the Italian Society of Neurology [90, 91]. Another important factor that supports delaying treatment in infected patients or who are at high risk of catching the infection is the link between alemtuzumab and the risk of stroke and cervicocephalic arterial dissection [92, 93]. This might augment the COVID-19-related risk of thrombosis and intracerebral hemorrhage [94] if patients are re-dosed with alemtuzumab during infection or if they catch the infection shortly after redosing. Staring a 
new treatment with alemtuzumab during the pandemic is not preferred and should only be considered if extremely necessary. Checking post-vaccination serology after receiving the future SARS-CoV-2 viral protein or inactivated vaccine is advisable in patients treated with alemtuzumab during the cell-depletion phase. Patients taking alemtuzumab who are in the depletion phase should follow strict social distancing and exposure reduction measures even if local lockdown rules have been lifted or eased down.

\subsection{Cladribine}

Cladribine is a potent oral immunosuppressant effective against MS relapses and lesion accumulation in the brain. It reached the primary outcome in a randomized, double-blind, placebo-controlled clinical trial published in 2010 [95].

\subsubsection{Mechanism of Action and Impact on the Immune System}

Cladribine is a purine nucleoside analog that inhibits DNA synthesis and repair in highly dividing cells inducing B- and T-cell apoptosis [96]. Its effect on T cells is less pronounced and short lived compared to B cells. Lymphopenia occurs during the depletion phase followed by the return of normal lymphocyte counts over several months. Contrary to alemtuzumab, the effect of cladribine on the innate immune cells is limited, although rare cases of neutropenia and pancytopenia have been described. Lymphocyte counts are monitored regularly prior to, during, and after therapy. Similar to alemtuzumab, immune reconstitution and resetting may occur after the second course eliminating the need for lifelong therapy.

\subsubsection{Infectious Side Effects}

In clinical studies, infections occurred in $49 \%$ of patients taking cladribine compared with $44 \%$ in the placebo group. There was a higher incidence of URTIs observed (38\% vs $32 \%$ ) [97]. In terms of serious infections, $6 \%$ of patients taking cladribine developed a herpetic infection compared with $2 \%$ in the placebo group. There was a higher incidence of herpes zoster infections in patients with severe lymphopenia of less than $500 / \mathrm{mm}^{3}$. Severe and fatal tuberculosis and hepatitis B infections have occurred with cladribine.

\subsubsection{Potential Relevance to the COVID-19 Pandemic and Possible Risk Mitigation Strategies}

Cladribine causes non-selective lymphopenia in the first 6 months after dosing and therefore it may reduce both the early and long-term immunity against SARS-CoV-2, increasing susceptibility and reinfection risks for patients exposed during the cell depletion phase. It can reduce both the humoral and cellular responses to the future SARSCoV-2 viral protein and inactivated vaccines. It will likely be incompatible with the live-attenuated and possibly viral vector vaccines. It might be relatively safer compared with alemtuzumab owing to its oral route of administration and lesser effect on T cells [98]. Although the oral route is safer compared with intravenous DMTs from the exposure risk standpoint, the need for periodic laboratory monitoring still carries a high exposure risk at the medical laboratory or with home collection personnel.

To the time of this writing, there have not been any confirmed cases of COVID-19 infection in patients receiving cladribine but one study found a trend towards higher COVID-19 suggestive symptoms in patients receiving cladribine compared with injectable therapies [99]. Patients in the depletion phase should follow strict social distancing measures even in areas where lockdown has been lifted or ameliorated. Delaying the second course of treatment should be considered during the pandemic especially in patients infected with COVID-19 based on published expert opinions and regional guidelines, although the value of this approach has not been proven yet $[66,90,91]$. Switching to a safer DMT should also be considered. Starting new treatment with cladribine is not preferred during the pandemic except if extremely necessary. As with other cell-depleting DMTs, checking post-vaccination serology is recommended when the future SARS-CoV-2 viral protein or inactivated vaccine becomes available. Patients in the immune reconstitution phase are unlikely to have increased infection-related risks.

\section{Discussion and Conclusions}

The global COVID-19 pandemic is expected to linger for several months and possibly years. Early reports on the risk of infection in patients with MS are largely reassuring [100], and a recent retrospective study did not find a difference in DMT utilization between patients with MS with mild COVID-19 infection and those with severe COVID-19 infection [101]. This highlights the importance of maintaining and initiating DMTs in patients with MS when indicated during the pandemic. However, the same study and several other reports suggest that different DMTs may be associated with different degrees of COVID-19-related risks. Therefore, clinical neuroimmunologists should have a basic understanding of the mechanism of action of each DMT and the potential interaction with the immune response against SARSCoV-2 and its future vaccine. The exposure risk related to each agent's route and the frequency of administration should also be considered. Infection-related risks should be weighed against the potency of the medication. 


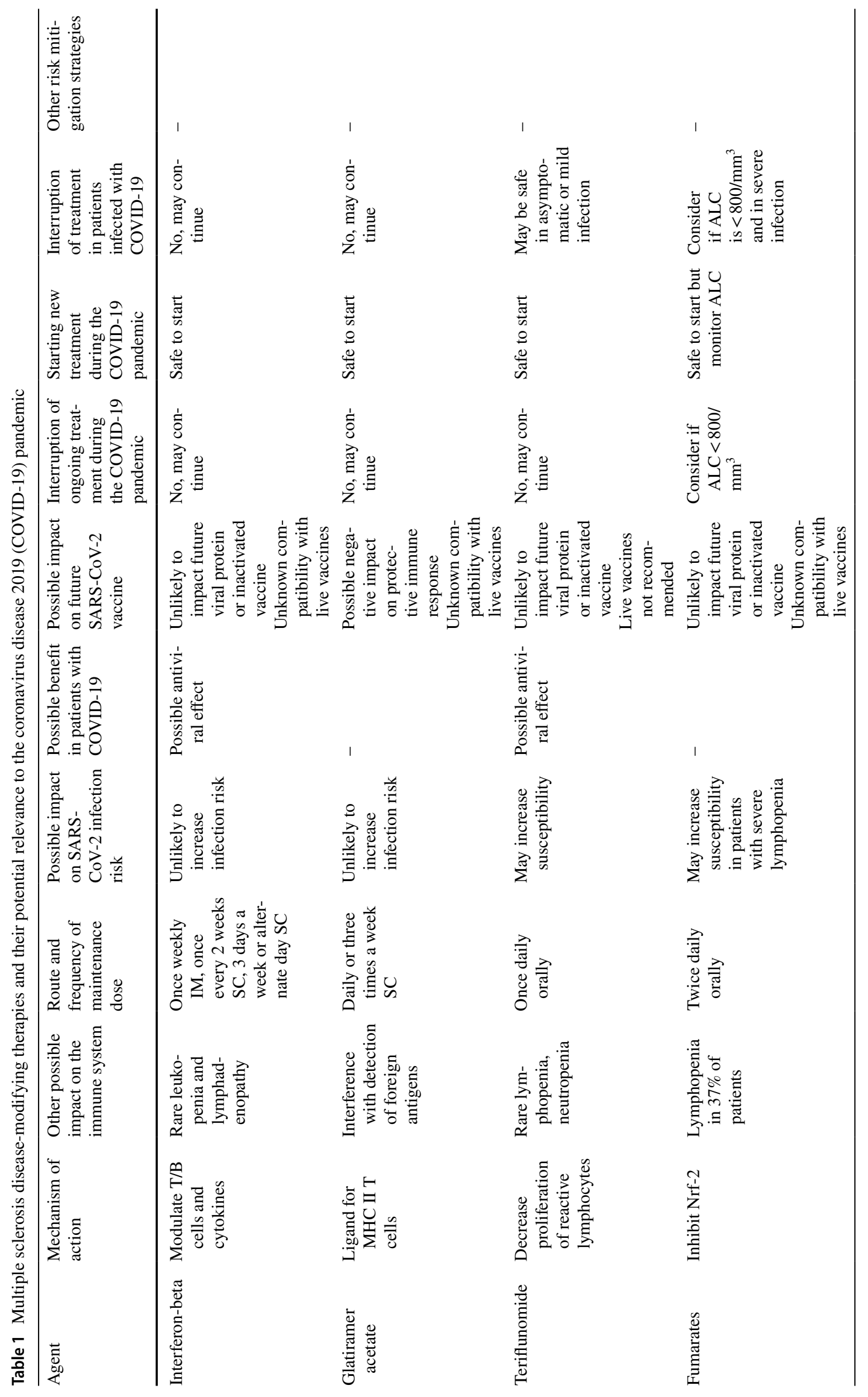




\begin{tabular}{|c|c|c|c|}
\hline 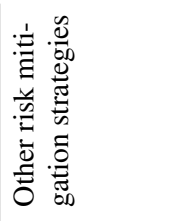 & 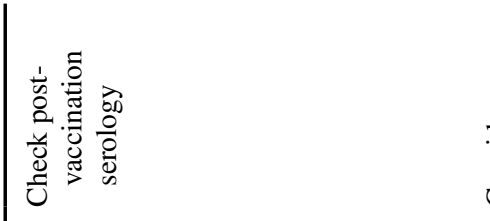 & 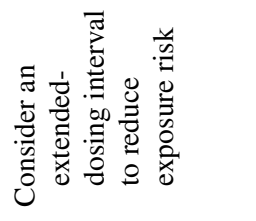 & 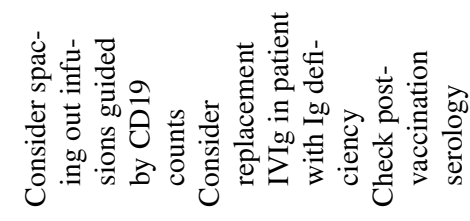 \\
\hline 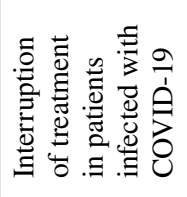 & 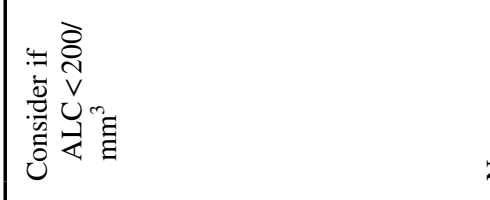 & 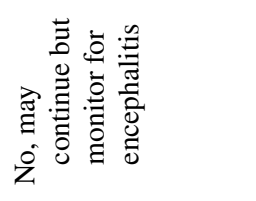 & 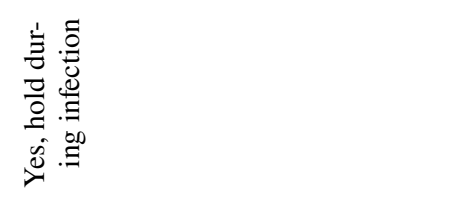 \\
\hline 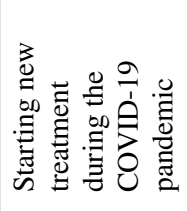 & 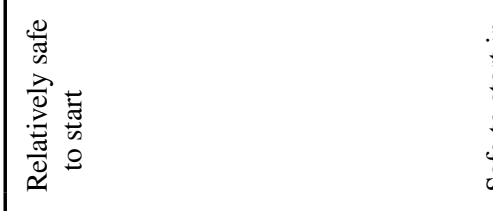 & 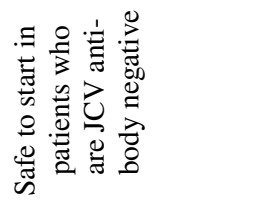 & 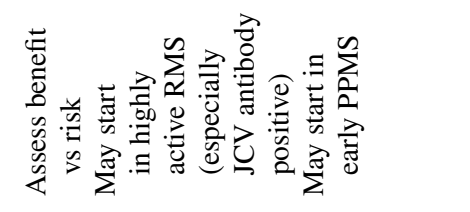 \\
\hline 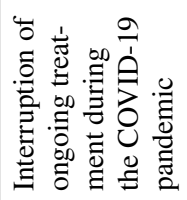 & 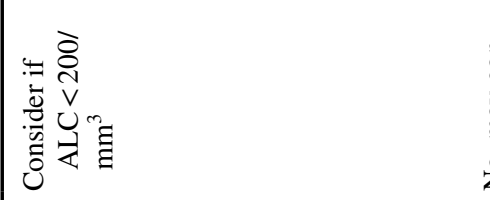 & 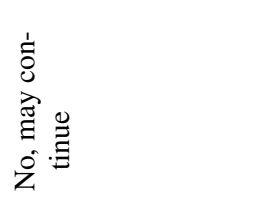 & 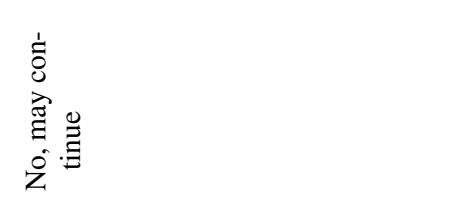 \\
\hline 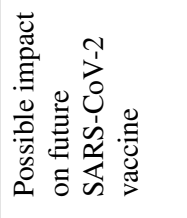 & 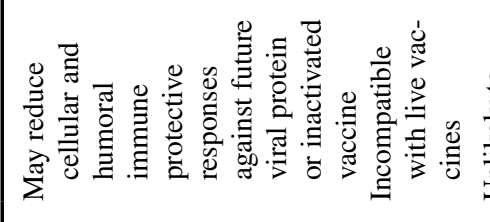 & 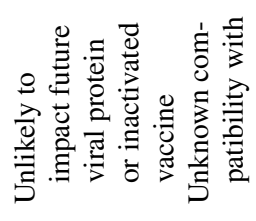 & 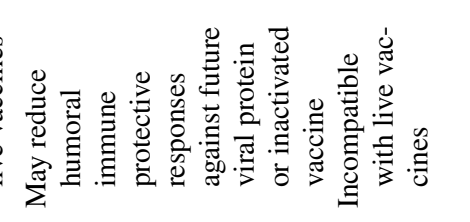 \\
\hline 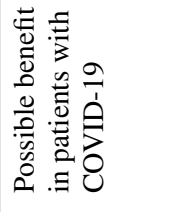 & 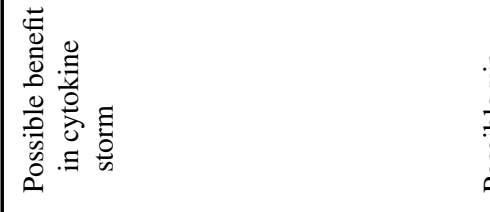 & 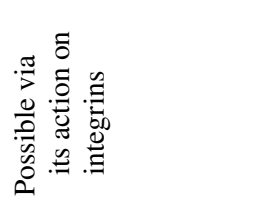 & I \\
\hline 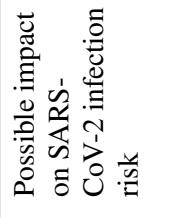 & 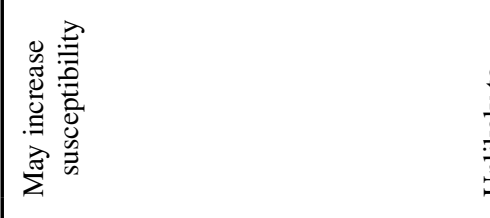 & 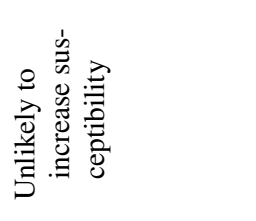 & 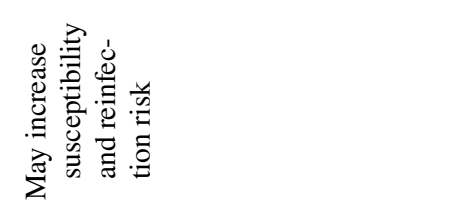 \\
\hline 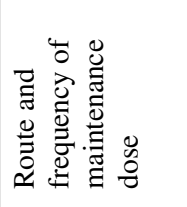 & 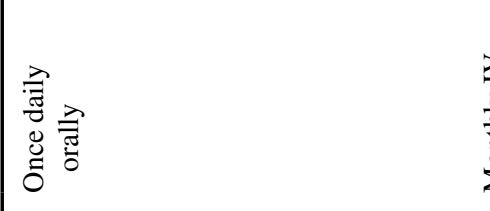 & 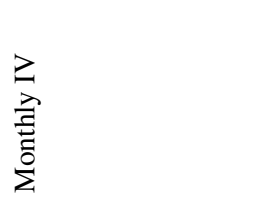 & 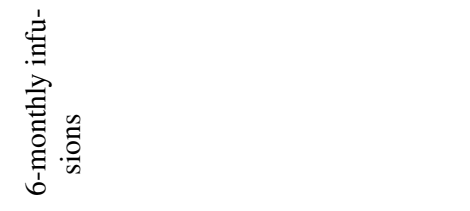 \\
\hline 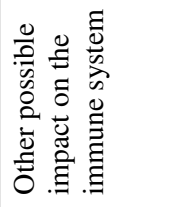 & 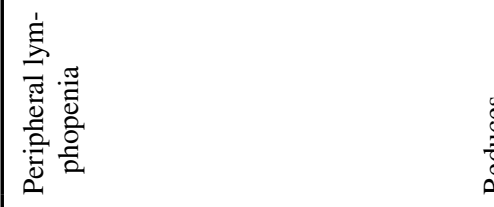 & 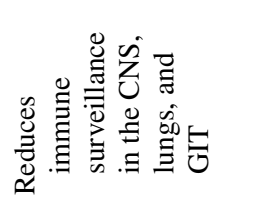 & 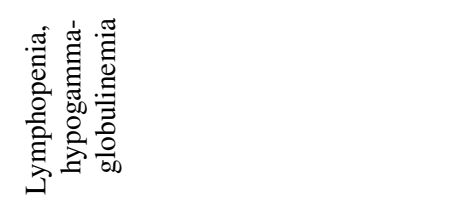 \\
\hline 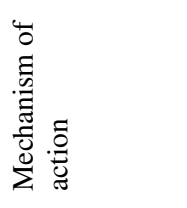 & 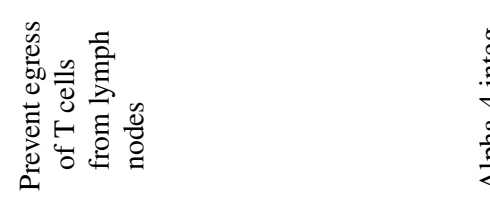 & 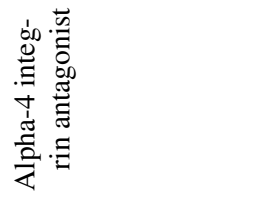 & 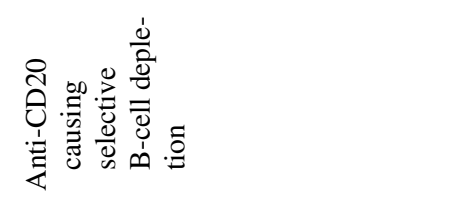 \\
\hline $\begin{array}{l}\overrightarrow{\bar{\Xi}} \\
\overrightarrow{8} \\
\overrightarrow{4}\end{array}$ & 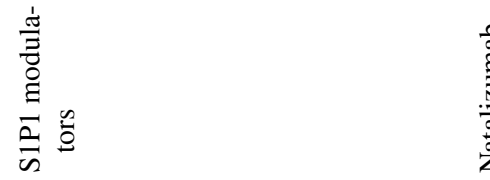 & 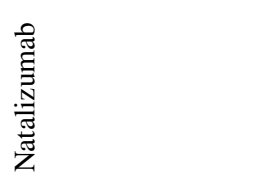 & 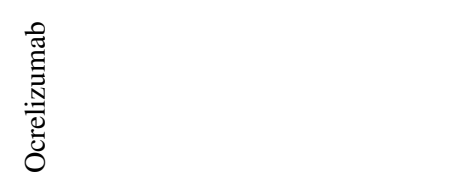 \\
\hline
\end{tabular}




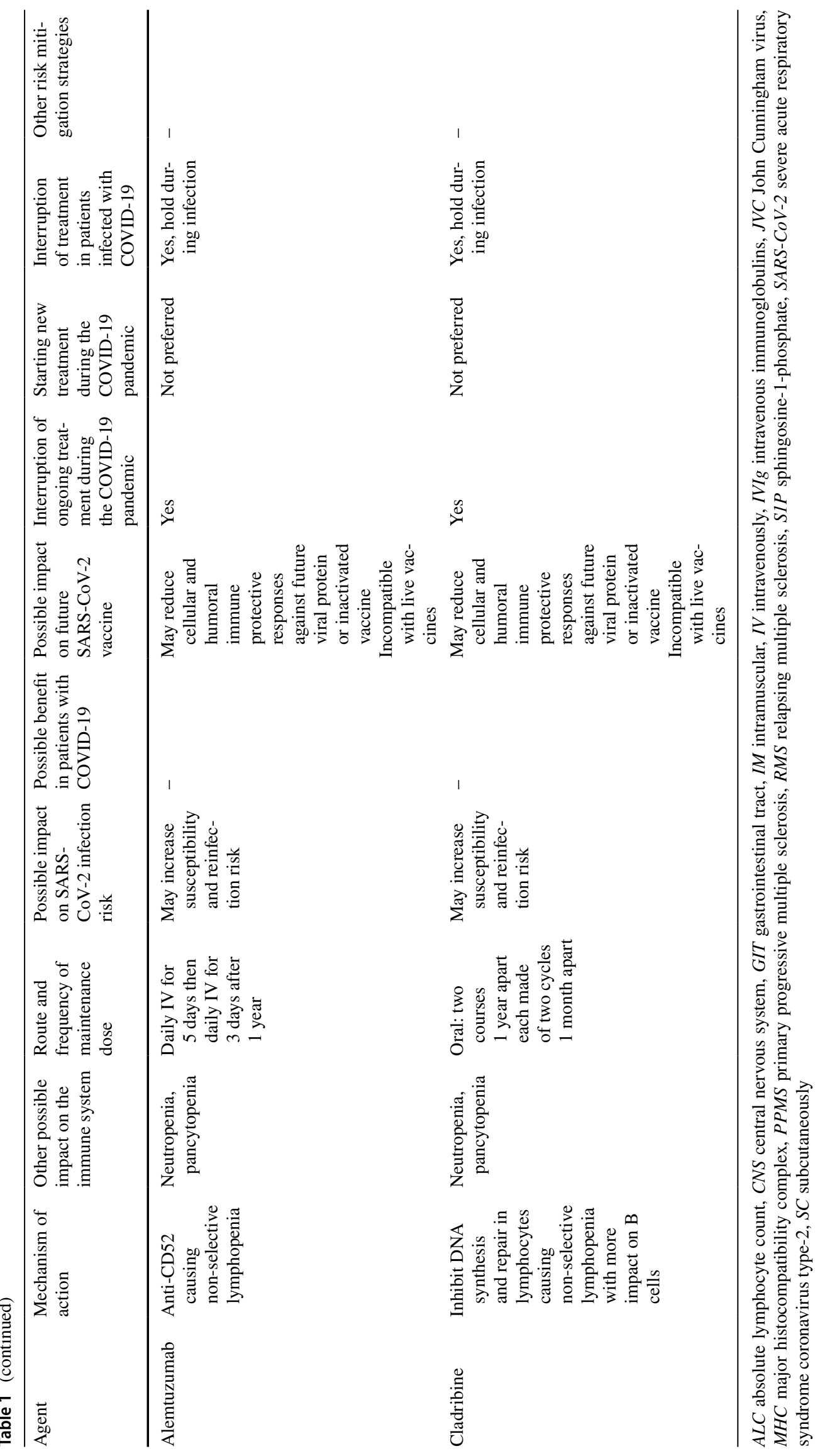




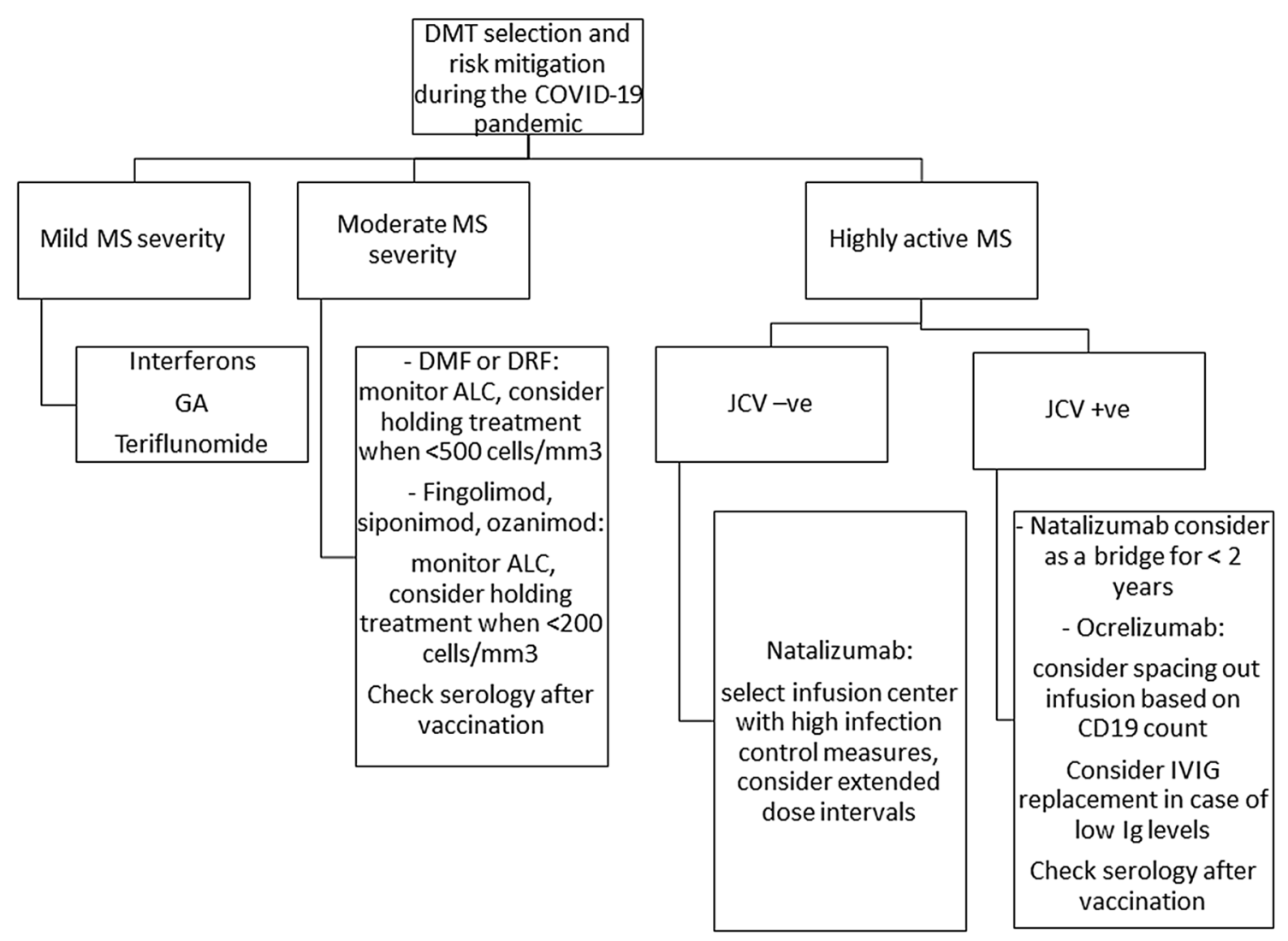

Fig. 1 Proposed practical approach to disease-modifying therapy (DMT) selection and risk mitigation during the coronavirus disease 2019 (COVID-19) pandemic. -ve negative, +ve positive, $A L C$ absolute lymphocyte count, CD19 cluster of differentiation 19, DMF

The ideal DMT during the pandemic is one with a moderate-to-high potency against MS without increasing the risk of SARS-CoV-2 exposure and susceptibility, and without a negative impact on the future vaccine. A potential benefit against the virus or its associated cytokine storm phase in infected patients is an additional factor to consider when deciding on DMT initiation. None of the existing DMTs fulfill all these criteria, thus a thorough discussion of the benefits and risks of each agent should take place prior to DMT initiation. Patient involvement in DMT selection has been an integral part of modern MS management but the relevance to the COVID-19 pandemic should now be part of the discussion and the decision-making process.

Conventional injectables probably have the safest immune profile and may need to be considered more frequently in patients with mild MS during the pandemic. The noncell-depleting oral agents are likely safer than cell-depleting agents from the mechanism of action standpoint and safer than all intravenous agents from the exposure risk standpoint. However, they each have their own disadvantages during the pandemic related to either low potency dimethyl fumarate, $D R F$ diroximel fumarate, $G A$ glatiramer acetate, Ig immunoglobulin, IVIG intravenous immunoglobulins, JCV John Cunningham virus, $M S$ multiple sclerosis

(teriflunomide), idiosyncratic lymphopenia (the fumarates), or a potential negative impact on future vaccine response (S1P modulators). Natalizumab is a relatively safe, highpotency DMT for patients who are JCV-IgG-negative during the pandemic but its monthly intravenous administration carries a high exposure risk. Among the cell-depleting DMTs, ocrelizumab is perhaps the safest but it should be used sparingly during the pandemic given its potential negative impact on infection risk and the response to the future SARS-CoV-2 vaccine. Cladribine may be relatively safer than alemtuzumab given the oral route of administration, the limited impact on innate immunity, and the relative sparing of T cells. However, both agents may increase the potential for infection-related risks and negatively impact the efficacy of the future SARS-CoV-2 vaccine during the lymphocyte depletion phase of treatment.

For patients who are currently taking DMT, continuation of the current DMT is preferred but some risk mitigation strategies should be considered when feasible. In high-risk patients in whom risk mitigation strategies are not possible, medication interruption or a switch may be needed. Table 1 
summarizes the potential relevance of each DMT to the COVID-19 pandemic along with suggested risk mitigation strategies. Figure 1 depicts a proposed practical approach to DMT selection and risk mitigation during the COVID-19 pandemic.

\section{Declarations}

Funding No sources of funding were received for the preparation of this article.

Conflict of Interest CZ, IK, CKC, and CS report no financial disclosures. SW is a consultant and a speaker for Biogen, Novartis, and Sanofi-Genzyme. AS is a consultant and speaker for Biogen and is supported in part by Career Development Award \#IK2RX001180 from the US Department of Veterans Affairs, Rehabilitation Research and Development Service. HA received research grants from Novartis and Genentech to conduct clinical trials. He received consulting fees from Biogen, Genentech, Alexion, and Viela Bio. He also received speaker honoraria from Biogen, Genentech, Celgene, Sanofi-Genzyme, Alexion, and Viela Bio.

Ethics approval Not applicable.

Consent to participate Not applicable.

Consent for publication Not applicable.

Availability of data and material Not applicable.

Code availability Not applicable.

Author Contributions $\mathrm{CZ}$ performed the literature search and wrote the first draft. IK, CKC, CS, SW, and AS reviewed, criticized, and revised the manuscript. HA conceptualized the review, performed the literature search, co-wrote the first draft, revised the manuscript, and is responsible for the final approval of the manuscript.

\section{References}

1. World Health Organization. Novel coronavirus situation report: 99. 28 April 2020. https://www.who.int/docs/default-source/ coronaviruse/situation-reports/20200428-sitrep-99-covid-19. pdf?sfvrsn=119fc381_2. Accessed 28 Apr 2020.

2. Prompetchara E, Ketloy C, Palaga T. Immune responses in COVID-19 and potential vaccines: lessons learned from SARS and MERS epidemic. Asian Pac J Allergy Immunol. 2020;38:1-9.

3. CDC. Coronavirus disease 2019 (COVID-19). https://www.cdc. gov/coronavirus/2019-ncov/faq.html. Accessed 15 Apr 2020.

4. MSIF. Global COVID-19 advice for people with MS. http://www. msif.org/wp-content/uploads/2020/03/MSIF-global-advice-onCOVID-19-for-people-with-MS.docx-1.pdf. Accessed 20 Mar 2020.

5. National Multiple Sclerosis Society. https://www.nationalmssocie ty.org/what-you-need-to-know-about-coronavirus-(COVID-19)/ DMT-guidelines-for-coronavirus-(COVID-19)-and. Accessed 20 Mar 2020.
6. Sigrist CJ, Bridge A, Le Mercier P. A potential role for integrins in host cell entry by SARS-CoV-2. Antivir Res. 2020;177:104759.

7. Cheng C, Xiaorong Z, Zhenyu J, et al. Research progress on the mechanism of cytokine storm induced by new coronavirus pneumonia and related immunotherapy. Zhonghua Shao Shang Za Zhi. 2020;36:E005.

8. Vabret N, Britton GJ, Gruber C, et al. Immunology of COVID19: current state of the science. Immunity. 2020;52(6):910-41. https://doi.org/10.1016/j.immuni.2020.05.002.

9. Diao B, Wang C, Tan Y, et al. Reduction and functional exhaustion of $\mathrm{T}$ cells in patients with coronavirus disease 2019 (COVID-19). Front Immunol. 2020;11:827. https://doi. org/10.3389/fimmu.2020.00827.

10. Ju B, Zhang Q, Ge J, et al. Human neutralizing antibodies elicited by SARS-CoV-2 infection. Nature. 2020. https://doi. org/10.1038/s41586-020-2380-z (Epub ahead of print).

11. Soresina A, Moratto D, Chiarini M, et al. Two X-linked agammaglobulinemia patients develop pneumonia as COVID-19 manifestation but recover. Pediatr Allergy Immunol. 2020. https://doi.org/10.1111/pai.13263 (Epub ahead of print).

12. Quinti I, Lougaris V, Milito C, et al. A possible role for B cells in COVID-19? Lesson from patients with agammaglobulinemia. J Allergy Clin Immunol. 2020;146(1):211-213.e4. https ://doi.org/10.1016/j.jaci.2020.04.013.

13. Mehta P, McAuley DF, Brown M, et al. COVID-19: consider cytokine storm syndromes and immunosuppression. Lancet. 2020;395(10229):1033-4. https://doi.org/10.1016/S0140 $-6736(20) 30628-0$.

14. Pedersen SF, Ho YC. SARS-CoV-2: a storm is raging. J Clin Investig. 2020;130(5):2202-5.

15. Qin C, Zhou L, Hu Z, et al. Dysregulation of immune response in patients with COVID-19 in Wuhan, China. Clin Infect Dis. 2020. https://doi.org/10.1093/cid/ciaa248 (Epub ahead of print).

16. Wu D, Yang XO. TH17 responses in cytokine storm of COVID19: an emerging target of JAK2 inhibitor Fedratinib. J Microbiol Immunol Infect. 2020;53(3):368-70. https://doi.org/10.1016/j. jmii.2020.03.005.

17. Zhou Y, Fu B, Zheng X, Wang D, Zhao C, Qi Y, et al. Pathogenic $\mathrm{T}$ cells and inflammatory monocytes incite inflammatory storm in severe COVID-19 patients. Natl Sci Rev. 2020. https://doi. org/10.1093/nsr/nwaa041 (Epub ahead of print).

18. Chen G, Wu D, Guo W, et al. Clinical and immunological features of severe and moderate coronavirus disease 2019. J Clin Investig. 2020;130(5):2620-9. https://doi.org/10.1172/JCI13 7244.

19. Thanh Le T, Andreadakis Z, Kumar A, et al. The COVID-19 vaccine development landscape. Nat Rev Drug Discov. 2020. https ://doi.org/10.1038/d41573-020-00073-5 (Epub ahead of print).

20. Jackson LA, Anderson EJ, Rouphael NG, et al. An mRNA vaccine against SARS-CoV-2: preliminary report. N Engl J Med. 2020. https://doi.org/10.1056/nejmoa2022483 (Epub ahead of print).

21. Kieseier BC. The mechanism of action of interferon- $\beta$ in relapsing multiple sclerosis. CNS Drugs. 2011;25(6):491-502.

22. Avonex (interferon beta-1a) [prescribing information]. Cambridge (MA): Biogen Idec Inc.; February 2012. https://www. avonex.com/content/dam/commercial/avonex/pat/en_us/pdf/ Avonex_US_Prescribing_Information.pdf. Accessed 28 July 2020.

23. Betaseron (interferon beta-1b) [prescribing information]. Whippany (NJ): Bayer Healthcare Pharmaceuticals Inc.; April 2016. https://labeling.bayerhealthcare.com/html/products/pi/Betas eron_PI.pdf. Accessed 28 July 2020. 
24. Winkelmann A, Loebermann M, Reisinger EC, et al. Multiple sclerosis treatment and infectious issues: update 2013. Clin Exp Immunol. 2014;175(3):425-38.

25. Hung IF, Lung KC, Tso EY, et al. Triple combination of interferon beta-1b, lopinavir-ritonavir, and ribavirin in the treatment of patients admitted to hospital with COVID-19: an open-label, randomised, phase 2 trial. Lancet. 2020;395(10238):1695-704. https://doi.org/10.1016/S0140-6736(20)31042-4.

26. Schwid SR, Decker MD, Lopez-Bresnahan M, Rebif-Influenza Vaccine Study Investigators. Immune response to influenza vaccine is maintained in patients with multiple sclerosis receiving interferon beta-1a. Neurology. 2005;65(12):1964-6.

27. Cohen JA, Barkhof F, Comi G, et al. Oral fingolimod or intramuscular interferon for relapsing multiple sclerosis. N Engl J Med. 2010;362:402-15.

28. Hauser SL, Bar-Or A, Comi G, et al. Ocrelizumab versus interferon beta-1a in relapsing multiple sclerosis. N Engl J Med. 2017;376(3):221-34

29. Cross AH, Naismith RT. Established and novel diseasemodifying treatments in multiple sclerosis. J Intern Med. 2014;275(4):350-63.

30. Copaxome (glatiramer acetate) [prescribing information]. 11 March 2014. Oakland Park (KS): Teva Neuroscience Inc.; January 2018. https://www.copaxone.com/globalassets/copaxone/ prescribing-information.pdf. Accessed 28 July 2020.

31. Pellegrino P, Carnovale C, Perrone V, et al. Efficacy of vaccination against influenza in patients with multiple sclerosis: the role of concomitant therapies. Vaccine. 2014;32(37):4730-5.

32. Metze C, Winkelmann A, Loebermann M, et al. Immunogenicity and predictors of response to a single dose trivalent seasonal influenza vaccine in multiple sclerosis patients receiving diseasemodifying therapies. CNS Neurosci Ther. 2019;25(2):245-54.

33. Olberg HK, Eide GE, Cox RJ, et al. Antibody response to seasonal influenza vaccination in patients with multiple sclerosis receiving immunomodulatory therapy. Eur J Neurol. 2018;25(3):527-34.

34. Fox RJ, Miller DH, Phillips JT, et al. Placebo controlled, phase 3 study of oral BG-12 or glatiramer in multiple sclerosis. N Engl J Med. 2012;367:1087-97.

35. Paolicelli D, Manni A, Iaffaldano A, Trojano M. Efficacy and safety of oral therapies for relapsing-remitting multiple sclerosis. CNS Drugs. 2020;34(1):65-92. https://doi.org/10.1007/s4026 3-019-00691-7.

36. Aubagio (teriflunomide) [prescribing information]. Cambridge (MA): Genzyme Corporation; September 2012. http://products. sanofi.us/Aubagio/aubagio.html. Accessed 28 July 2020.

37. Gilli F, Li L, Royce DB, et al. Treatment of Theiler's virusinduced demyelinating disease with teriflunomide. J Neurovirol. 2017;23(6):825-38.

38. Bowen JD, Brink J, Brown TR, et al. COVID-19 in MS: initial observations from the Pacific Northwest. Neurol Neuroimmunol Neuroinflamm. 2020;7(5):e783. https://doi.org/10.1212/ NXI.0000000000000783.

39. Maghzi AH, Houtchens MK, Preziosa P, et al. COVID-19 in teriflunomide-treated patients with multiple sclerosis. J Neurol. 2020. https://doi.org/10.1007/s00415-020-09944-8 (Epub ahead of print).

40. Möhn N, Saker F, Bonda V, et al. Mild COVID-19 symptoms despite treatment with teriflunomide and high-dose methylprednisolone due to multiple sclerosis relapse. J Neurol. 2020. https://doi.org/10.1007/s00415-020-09921-1 (Epub ahead of print).

41. Luca B, Tommaso G, Bavaro DF, et al. Seroconversion and indolent course of COVID-19 in patients with multiple sclerosis treated with fingolimod and teriflunomide. J Neurol Sci.
2020;416:117011. https://doi.org/10.1016/j.jns.2020.117011 (Epub ahead of print).

42. Nesbitt C, Rath L, Yeh WZ, et al. MSCOVID19: using social media to achieve rapid dissemination of health information. Mult Scler Relat Disord. 2020;45:102338. https://doi. org/10.1016/j.msard.2020.102338 (Epub ahead of print).

43. Bar-Or A, Freedman MS, Kremenchutzky M, et al. Teriflunomide effect on immune response to influenza vaccine in patients with multiple sclerosis. Neurology. 2013;81(6):552-8.

44. O'Connor P, Wolinsky JS, Confavreux C, et al. Randomized trial of oral teriflunomide for relapsing multiple sclerosis. $\mathrm{N}$ Engl J Med. 2011;365(14):1293-303. https://doi.org/10.1056/ NEJMoa1014656.

45. Confavreux C, O'Connor P, Comi G, et al. Oral teriflunomide for patients with relapsing multiple sclerosis (TOWER): a randomized, double-blind, placebo-controlled, phase 3 trial. Lancet Neurol. 2014;13(3):247-56.

46. Naismith RT, Wundes A, Ziemssen T, et al. Diroximel fumarate demonstrates an improved gastrointestinal tolerability profile compared with dimethyl fumarate in patients with relapsing-remitting multiple sclerosis: results from the randomized, double-blind, phase III EVOLVE-MS-2 study. CNS Drugs. 2020;34(2):185-96. https://doi.org/10.1007/s40263-020-00700 -0 .

47. Fox RJ, Chan A, Gold R, et al. Characterizing absolute lymphocyte count profiles in dimethyl fumarate-treated patients with MS: patient management considerations. Neurol Clin Pract. 2016;6(3):220-9.

48. Vumerity (diroximel fumarate) [prescribing information]. Waltham (MA): Alkermes Inc.; October 2019. https://www. vumerityhcp.com/content/dam/commercial/vumerity/hcp/ en_us/pdf/vumerity-prescribing-information.pdf. Accessed 28 July 2020.

49. Diebold M, Altersberger V, Décard BF, Kappos L, Derfuss $\mathrm{T}$, Lorscheider J. A case of progressive multifocal leukoencephalopathy under dimethyl fumarate treatment without severe lymphopenia or immunosenescence. Mult Scler. 2019;25(12):1682-5. https://doi.org/10.1177/1352458519 852100.

50. Mantero V, Abate L, Basilico P, et al. COVID-19 in dimethyl fumarate-treated patients with multiple sclerosis. J Neurol. 2020. https://doi.org/10.1007/s00415-020-10015-1 (Epub ahead of print).

51. Von Hehn C, Howard J, Liu S, et al. Immune response to vaccines in maintained in patients treated with dimethyl fumarate. Neurol Neuroimmunol Neuroinflamm. 2018;5(1):e409.

52. Cohen JA, Comi G, Selmaj KW, et al. Safety and efficacy of ozanimod versus interferon beta-1a in relapsing multiple sclerosis (RADIANCE): a multicentre, randomised, 24-month, phase 3 trial. Lancet Neurol. 2019;18(11):1021-33. https:// doi.org/10.1016/S1474-4422(19)30238-8.

53. Gilenya (fingolimod) [prescribing information]. East Hanover (NJ): Novartis Pharmaceutical Corporation; May 2012. https ://www.novartis.us/sites/www.novartis.us/files/gilenya.pdf. Accessed 28 July 2020.

54. Mayzent (siponimod) [prescribing information]. East Hanover (NJ): Novartis Pharmaceutical Corporation; March 2019. https ://www.novartis.us/sites/www.novartis.us/files/mayzent.pdf. Accessed 28 July 2020.

55. Zeposia (ozanimod) [prescribing information]. Summit (NJ): Celgene Corporation; March 2020. https://packageinserts.bms. com/pi/pi_zeposia.pdf. Accessed 28 July 2020.

56. Gomez-Mayordomo V, Montero-Escribano P, Matías-Guiu JA, González-García N, Porta-Etessam J, Matías-Guiu J. Clinical exacerbation of SARS-CoV2 infection after fingolimod 
withdrawal. J Med Virol. 2020. https://doi.org/10.1002/ jmv.26279 (Epub ahead of print).

57. Valencia-Sanchez C, Wingerchuk DM. A fine balance: immunosuppression and immunotherapy in a patient with multiple sclerosis and COVID-19. Mult Scler Relat Disord. 2020;42:102182. https://doi.org/10.1016/j.msard.2020.10218 2.

58. Fox EJ, Buckle GJ, Singer B, Singh V, Boster A. Lymphopenia and DMTs for relapsing forms of MS: considerations for the treating neurologist [published correction appears in Neurol Clin Pract. 2019 Jun;9(3):184]. Neurol Clin Pract. 2019;9(1):53-63.

59. Barry B, Erwin AA, Stevens J, et al. Fingolimod rebound: a review of the clinical experience and management considerations. Neuro Ther. 2019;8:241-50.

60. Barzegar M, Mirmosayyeb O, Nehzat N, et al. COVID-19 infection in a patient with multiple sclerosis treated with fingolimod. Neurol Neuroimmunol Neuroinflamm. 2020;7(4):e753. https:// doi.org/10.1212/NXI.0000000000000753/.

61. Foerch C, Friedauer L, Bauer B, Wolf T, Adam EH. Severe COVID-19 infection in a patient with multiple sclerosis treated with fingolimod. Mult Scler Relat Disord. 2020;42:102180. https ://doi.org/10.1016/j.msard.2020.102180.

62. Chiarini M, Paghera S, Moratto D, et al. Immunologic characterization of a immunosuppressed multiple sclerosis patient that recovered from SARS-CoV-2 infection. J Neuroimmunol. 2020;345:577282. https://doi.org/10.1016/j.jneur oim.2020.577282.

63. Kappos L, Mehling M, Arroyo R, et al. Randomized trial of vaccination in fingolimod-treated patients with multiple sclerosis. Neurology. 2015;84(9):872-9.

64. Tysabri (natalizumab) [prescribing information]. Cambridge (MA): Biogen Idec Inc.; August 2019. https://www.tysabri.com/ content/dam/commercial/tysabri/pat/en_us/pdf/tysabri_presc ribing_information.pdf?cid=PPC-MICROSOFT-Tysabri_DTC_ Branded_Phrase $\sim$ S PH $\sim$ BR NER DTC BR-natalizumab-NAp31547638597\&\&msclkid=ba0b5edf571d1d26140801cd7edd34 cb\&gclid=ba0b5edf571d1d26140801cd7edd34cb\&gclsrc $=3 \mathrm{p}$. ds. Accessed 28 July 2020.

65. Vågberg M, Kumlin U, Svenningsson A. Humoral immune response to influenza vaccine in natalizumab-treated MS patients. Neurol Res. 2012;34(7):730-3.

66. Giovannoni G, Hawkes C, Lechner-Scott J, Levy M, Waubant $\mathrm{E}$, Gold J. The COVID-19 pandemic and the use of MS diseasemodifying therapies. Mult Scler Relat Disord. 2020;39:102073. https://doi.org/10.1016/j.msard.2020.102073.

67. Zhovtis Ryerson L, Frohman TC, Foley J, et al. Extended interval dosing of natalizumab in multiple sclerosis. J Neurol Neurosurg Psychiatry. 2016;87(8):885-9.

68. Borriello G, Ianniello A. COVID-19 occurring during Natalizumab treatment: a case report in a patient with extended interval dosing approach. Mult Scler Relat Disord. 2020;41:102165. https ://doi.org/10.1016/j.msard.2020.102165.

69. Aguirre C, Meca-Lallana V, Barrios-Blandino A, Del Río B, Vivancos J. Covid-19 in a patient with multiple sclerosis treated with natalizumab: may the blockade of integrins have a protective role? Mult Scler Relat Disord. 2020;44:102250. https://doi. org/10.1016/j.msard.2020.102250 (Epub ahead of print).

70. Montalban X, Hauser SL, Kappos L, et al. Ocrelizumab versus placebo in primary progressive multiple sclerosis. N Engl J Med. 2017;376(3):209-20. https://doi.org/10.1056/NEJMoa1606468.

71. Derfuss T, Weber MS, Hughes R, et al. Serum immunoglobulin levels and risk of serious infections in the pivotal phase III trials of ocrelizumab in multiple sclerosis and their open-label extensions. Paper presented at the 2019 European Committee for Treatment and Research in Multiple Sclerosis (ECTRIMS) annual meeting, Stockholm, 11-13 Sept 2019.
72. Roberts DM, Jones RB, Smith RM, et al. Rituximab-associated hypogammaglobulinemia: incidence, predictors and outcomes in patients with multi-system autoimmune disease. J Autoimmun. 2015;57:60-5.

73. Ocrevus (ocrelizumab) [prescribing information]. South San Francisco (CA): Genentech Inc.; March 2017. https://www.gene. com/download/pdf/ocrevus_prescribing.pdf\#: :text=FULL\%20 PRESCRIBING\%20INFORMATION\% 201\%20INDICATI ONS \%20AND $\%$ 20USAGE. $\% 20$ OCREVUS,in $\%$ 20adults $\% 20$ $\%$ E2\% $80 \%$ A2\%20Primary\%20progressive $\% 20 \mathrm{MS} \% 2 \mathrm{C} \% 20$ in $\% 20$ adults. Accessed 28 July 2020.

74. Chen X, Jensen PE. The role of B lymphocytes as antigen-presenting cells. Arch Immunol Ther Exp (Warsz). 2008;56(2):77-83.

75. Safavi F, Nourbakhsh B, Azimi AR. B-cell depleting therapies may affect susceptibility to acute respiratory illness among patients with multiple sclerosis during the early COVID-19 epidemic in Iran. Mult Scler Relat Disord. 2020;43:102195. https:// doi.org/10.1016/j.msard.2020.102195 (Epub ahead of print).

76. Meca-Lallana V, Aguirre C, Río B, Cardeñoso L, Alarcon T, Vivancos J. COVID-19 in 7 multiple sclerosis patients in treatment with ANTI-CD20 therapies. Mult Scler Relat Disord. 2020;44:102306. https://doi.org/10.1016/j.msard.2020.102306 (Epub ahead of print).

77. Thornton JR, Harel A. Negative SARS-CoV-2 antibody testing following COVID-19 infection in two MS patients treated with ocrelizumab. Mult Scler Relat Disord. 2020;44:102341. https:// doi.org/10.1016/j.msard.2020.102341 (Epub ahead of print).

78. Lucchini M, Bianco A, Del Giacomo P, De Fino C, Nociti V, Mirabella M. Is serological response to SARS-CoV-2 preserved in MS patients on ocrelizumab treatment? A case report. Mult Scler Relat Disord. 2020;44:102323. https://doi.org/10.1016/j. msard.2020.102323 (Epub ahead of print).

79. Conte WL. Attenuation of antibody response to SARS-CoV-2 in a patient on ocrelizumab with hypogammaglobulinemia. Mult Scler Relat Disord. 2020;44:102315. https://doi.org/10.1016/j. msard.2020.102315 (Epub ahead of print).

80. Van Assen S, Holvast A, Benne CA, et al. Humoral responses after influenza vaccination are severely reduced in patients with rheumatoid arthritis treated with rituximab. Arthritis Rheum. 2010;62:75-81.

81. Hughes R, Pedotti R, Koendgen H. COVID-19 in persons with multiple sclerosis treated with ocrelizumab: a pharmacovigilance case series. Mult Scler Relat Disord. 2020. https://doi. org/10.1016/j.msard.2020.102192 (Epub ahead of print).

82. Montero-Escribano P, Matías-Guiu J, Gómez-Iglesias P, PortaEtessam J, Pytel V, Matias-Guiu JA. Anti-CD20 and COVID19 in multiple sclerosis and related disorders: a case series of 60 patients from Madrid, Spain. Mult Scler Relat Disord. 2020;42:102185. https://doi.org/10.1016/j.msard.2020.102185 (Epub ahead of print).

83. Novi G, Mikulska M, Briano F, et al. COVID-19 in a MS patient treated with ocrelizumab: does immunosuppression have a protective role? Mult Scler Relat Disord. 2020;42:102120. https:// doi.org/10.1016/j.msard.2020.102120.

84. Ghajarzadeh M, Mirmosayyeb O, Barzegar M, et al. Favorable outcome after COVID-19 infection in a multiple sclerosis patient initiated on ocrelizumab during the pandemic. Mult Scler Relat Disord. 2020;43:102222. https://doi.org/10.1016/j.msard .2020.102222.

85. Gross CC, Ahmetspahic D, Ruck T, et al. Alemtuzumab treatment alters circulating innate immune cells in multiple sclerosis. Neurol Neuroimmunol Neuroinflamm. 2016;3(6):e289. https:// doi.org/10.1212/NXI.0000000000000289. 
86. Lemtrada (alemtuzumab) [prescribing information]. Cambridge (MA): Genzyme Corporation; October 2017. http://products. sanofi.us/Lemtrada/Lemtrada.html. Accessed 28 July 2020.

87. Guevara C, Villa E, Cifuentes M, Naves R, Grazia J. Mild COVID-19 infection in a patient with multiple sclerosis and severe depletion of T-lymphocyte subsets due to alemtuzumab. Mult Scler Relat Disord. 2020;44:102314. https://doi. org/10.1016/j.msard.2020.102314 (Epub ahead of print).

88. Carandini T, Pietroboni AM, Sacchi L, et al. Alemtuzumab in multiple sclerosis during the COVID-19 pandemic: a mild uncomplicated infection despite intense immunosuppression. Mult Scler. 2020. https://doi.org/10.1177/1352458520926459 (Epub ahead of print).

89. Matías-Guiu J, Montero-Escribano P, Pytel V, Porta-Etessam J, Matias-Guiu JA. Potential COVID-19 infection in patients with severe multiple sclerosis treated with alemtuzumab. Mult Scler Relat Disord. 2020;11(44):102297. https://doi.org/10.1016/j. msard.2020.102297.

90. Brownlee W, Bourdette D, Broadley S, Killestein J, Ciccarelli O. Treating multiple sclerosis and neuromyelitis optica spectrum disorder during the COVID-19 pandemic. Neurology. 2020;94(22):949-52. https://doi.org/10.1212/WNL.0000000000 009507.

91. https://cdn.ymaws.com/www.theabn.org/resource/collection /6750BAE6-4CBC-4DDB-A684-/116E03BFE634/ABN_Guida nce_on_DMTs_for_MS_and_COVID19.pdf. Accessed 10 July 2020.

92. Durand-Dubief F, Marignier R, Berthezene Y, Cottin J, Nighoghossian N, et al. Spontaneous multiple cervical artery dissections after alemtuzumab. Mult Scler. 2020;26(3):381-3. https://doi. org/10.1177/1352458519828663.

93. FDA Drug Safety Communication. FDA warns about rare but serious risks of stroke and blood vessel wall tears with multiple sclerosis drug Lemtrada (alemtuzumab). https://www.fda.gov/ Drugs/DrugSafety/ucm624247.htm. Accessed 10 July 2020.

94. Oxley TJ, Mocco J, Majidi S, et al. Large-vessel stroke as a presenting feature of Covid-19 in the young. N Engl J Med. 2020;382(20):e60. https://doi.org/10.1056/NEJMc2009787.

95. Giovannoni G, Comi G, Cook S, et al. A placebo-controlled trial of oral cladribine for relapsing multiple sclerosis. N Engl J Med. 2010;362(5):416-26. https://doi.org/10.1056/NEJMoa0902533.

96. Giovannoni G. Cladribine to treat relapsing forms of multiple sclerosis. Neurotherapeutics. 2017;14(4):874-87. https://doi. org/10.1007/s13311-017-0573-4.

97. Mavenclad (cladribine) [prescribing information]. Rockland (MA): EMD Serono Inc.; 2019. https://www.emdserono.com/ us-en/pi/mavenclad-pi.pdf. Accessed 28 July 2020.

98. Stuve O, Soelberg Soerensen P, Leist T, et al. Effects of cladribine tablets on lymphocyte subsets in patients with multiple sclerosis: an extended analysis of surface markers. Ther Adv Neurol Disord. 2019;12:1756286419854986.

99. Dalla Costa G, Leocani L, Montalban X, et al. Real-time assessment of COVID-19 prevalence among multiple sclerosis patients: a multicenter European study. Neurol Sci. 2020. https://doi. org/10.1007/s10072-020-04519-x (Epub ahead of print).

100. Sormani MP. Italian Study Group on COVID-19 infection in multiple sclerosis. An Italian programme for COVID-19 infection in multiple sclerosis [published correction appears in Lancet Neurol. 2020 May 28]. Lancet Neurol. 2020;19(6):481-2. https ://doi.org/10.1016/s1474-4422(20)30147-2.

101. Louapre C, Collongues N, Stankoff B, et al. Clinical characteristics and outcomes in patients with coronavirus disease 2019 and multiple sclerosis. JAMA Neurol. 2020. https://doi.org/10.1001/ jamaneurol.2020.2581 (Epub ahead of print).

\section{Affiliations}

\section{Crystal Zheng ${ }^{1} \cdot$ Indrani Kar $^{2} \cdot$ Claire Kaori Chen ${ }^{3} \cdot$ Crystal Sau $^{3,4} \cdot$ Sophia Woodson $^{4} \cdot$ Alessandro Serra $^{4,5}$. Hesham Abboud ${ }^{4}$ (i)}

1 Raabe College of Pharmacy, Ohio Northern University, Ada, $\mathrm{OH}$, USA

2 System Pharmacy Services, University Hospitals of Cleveland, Cleveland, OH, USA

3 Specialty Pharmacy, University Hospitals of Cleveland, Cleveland, OH, USA

4 Multiple Sclerosis and Neuroimmunology Program, University Hospitals of Cleveland, Case Western Reserve
University School of Medicine, Cleveland Medical Center, Bolwell, 5th Floor, 11100 Euclid Avenue, Cleveland, OH 44106, USA

5 VA Multiple Sclerosis Center of Excellence, Cleveland VA Medical Center, Cleveland, OH, USA 